\title{
Ascorbic Acid Contents in Chili Peppers (Capsicum L.)
}

\author{
Owk ANIEL KUMAR ${ }^{1)}$, Sape SUBBA TATA ${ }^{2)}$ \\ 1) Andhra University, Department of Botany,Visakhapatnam, India; owkanielkumar@yahoo.com \\ 2) Andhra University, Department of Botany,Visakhapatnam,India;s_tata_s@yahoo.co.in (correspondingauthor)
}

\begin{abstract}
The genus Capsicum commonly known as chili pepper is a major spice crop and is almost cosmopolitan in distribution. The nutritive value of chili pepper is largely determined by ascorbic acid content. The fruits at five ripening stages viz., $\left(M_{1}, M_{2}, M_{3}, M_{4}\right.$ and $\left.M_{5}\right)$ from seventeen cultivars of Capsicum annuum $\mathrm{L}$ and one cultivar of Capsicum frutescens $\mathrm{L}$ were analyzed for ascorbic acid content. Among eighteen genotypes the $C$. annuum var. IC: $119262\left(\mathrm{CA}_{2}\right)$ showed higher ascorbic acid content $(\mathrm{mg} / 100 \mathrm{~g}) \mathrm{FW}$ i.e., $208.0 \pm 0.68\left(\mathrm{M}_{1}\right)$, $231.0 \pm 0.66\left(\mathrm{M}_{2}\right), 280.0 \pm 0.31\left(\mathrm{M}_{3}\right), 253.0 \pm 0.34\left(\mathrm{M}_{4}\right)$ and $173.7 \pm 0.27\left(\mathrm{M}_{5}\right)$. The study revealed that the gradual increase in ascorbic acid content from green to red and subsequently declined in the lateral stages (red partially dried and red fully dried fruits). The variability of ascorbic acid content in the genotypes suggests that these selected genotypes may be use full as parents in hybridization programs to produce fruits with good nutritional values.
\end{abstract}

Keywords: Capsicum L., ascorbic acid, ripening, 2, 4. dinitrophenylhydrazine

\section{Introduction}

A wealth of information and scientific evidences are rapidly accumulating the beneficial effects of wide variety of food components on human health. The most important vitamin in fruits and vegetables is vitamin C 90\% of the ascorbic acid in human diet was supplied by them. Chili peppers are the most important vegetable cum spice because of its colour, taste, pungency, flavour and aroma grown in tropical and sub tropical regions of the world. They are extremely popular for the abundance content of vitamin $C$ larger than other vegetables and fruits commonly recognized as a source of this substance (Durust et al., 1997; Osuna-Garcia et al. 1998). The ascorbic acid (Vitamin C) content in chili peppers has been reported by few workers (Howard et al., 1994; Lee et al., 1995; Mishra, 2004; Sheela, 2004). Large varietal variations in ascorbic acid content have been reviewed by Manju $e t$ al. (2002) and Antonious et al. (2006). Ascorbic acid content was increases with fruit ripening while, losses during post harvest handlings (Martinez et al., 2005). Despite many reports of ascorbic acid content in chili peppers is inadequate. There fore the present study is taken up to estimate the content of ascorbic acid during ripening in eighteen genotypes of chili peppers (Capsicum L) and to select genotypes having high content of ascorbic acid as parents in breeding programs.

\section{Materials and methods}

Seventeen cultivars of $C$. annuum $\mathrm{L}$ and one cultivar of Capsicum frutescens $\mathrm{L}$ were grown in randomized design with three replicates at the experimental farm of Andhra University, Visakhapatnam. The healthy fruits were harvested at five ripening stages viz., Green $\left(M_{1}\right)$, Breaker $\left(\mathrm{M}_{2}\right)$, Red $\left(\mathrm{M}_{3}\right)$, Red partially dried $\left(\mathrm{M}_{4}\right)$ and Red fully dried $\left(M_{5}\right)$. The fruits were washed with tap water and cut into small pieces and homogenized with the help of mortar and pestle by adding $5 \mathrm{ml}$ of $4 \%$ oxalic acid. The homogenates were centrifuged at $5000 \mathrm{rpm}$ for 10 minutes then the supernatants were filtered with 541 Whatmann filter paper the obtained residues were made up to $25 \mathrm{ml}$ with $4 \%$ oxalic acid. The ascorbic acid content was estimated by using 2, 4. dinitrophenylhydrazine reagent in conjunction with spectrophotometer at $540 \mathrm{~nm}$ (Sadasivam and Manickam, 1992) five samples from each lot were analyzed.

\section{Results and discussion}

From the (Tab. 1 and Fig. 1) shows that a gradual increase of ascorbic acid content from green to red ripening while, decreased in the lateral stages (i.e., red partially dried and red fully dried) these results were agreed according to the data reported by Osuna- Garcia et al. (1998) and Martinez et al. (2005). The genotypes showed considerable variation in ascorbic acid content ranged from $44.3 \mathrm{mg}$ to $280 \mathrm{mg} / 100 \mathrm{~g}$ FW and were categorized under hot peppers in agreement with previous observations (Howard et al., 1994; Lee et al., 1995; Manju et al., 2002; Antonious, et al. 2006). Among the eighteen genotypes $C$. annuum var.IC: $119262\left(\mathrm{CA}_{2}\right)$ showed highest ascorbic acid content in all the ripening stages i.e., $208.0 \pm 0.68$ (green),


partially dried) and $173.7 \pm 0.27$ (red fully dried) while, 
Tab. 1. Mean ascorbic acid contents in eighteen genotypes of chili peppers (Capsicum L.) at five ripening stages.

\begin{tabular}{|c|c|c|c|c|c|}
\hline \multirow[b]{3}{*}{ Genotype } & \multicolumn{5}{|c|}{ Ascorbic acid content $\mathrm{mg} / 100 \mathrm{~g}$ of fruit fresh weight } \\
\hline & \multirow[b]{2}{*}{ Green $\left(M_{1}\right)$} & \multicolumn{3}{|c|}{ Stage of ripening } & \multirow[b]{2}{*}{$\begin{array}{c}\text { Red fully } \\
\text { dried }\left(\mathrm{M}_{5}\right)\end{array}$} \\
\hline & & Breaker $\left(\mathrm{M}_{2}\right)$ & $\operatorname{Red}\left(\mathrm{M}_{3}\right)$ & $\begin{array}{l}\text { Red partially } \\
\text { dried }\left(\mathrm{M}_{4}\right)\end{array}$ & \\
\hline C.annuum var. IC:119243 (CA $)$ & $122.8 \pm 0.89$ & $139.0 \pm 0.17$ & $197.5 \pm 0.18$ & $168.5 \pm 0.65$ & $103.2 \pm 0.38$ \\
\hline C.annuum var. IC:119262 (CA $)$ & $208.0 \pm 0.68$ & $231.0 \pm 0.66$ & $280.0 \pm 0.31$ & $253.0 \pm 0.34$ & $173.7 \pm 0.27$ \\
\hline C.annuum var. IC:119264 (CA $)$ & $157.0 \pm 0.64$ & $180.2 \pm 0.38$ & $234.0 \pm 0.41$ & $205.0 \pm 0.70$ & $128.5 \pm 0.18$ \\
\hline C.annuum var. IC:119267 (CA $)$ & $107.0 \pm 1.30$ & $136.8 \pm 0.29$ & $180.6 \pm 0.36$ & $149.0 \pm 0.96$ & $84.0 \pm 0.66$ \\
\hline C.annuum var. IC:119578 (CA $)$ & $150.6 \pm 0.48$ & $175.0 \pm 0.65$ & $227.0 \pm 0.71$ & $200.0 \pm 0.95$ & $133.8 \pm 0.95$ \\
\hline C.annuum var.NIC:20901 (CA $)$ & $130.0 \pm 0.95$ & $140.5 \pm 0.63$ & $210.5 \pm 0.20$ & $185.0 \pm 0.35$ & $110.0 \pm 0.65$ \\
\hline C. annuum var.IC:147719 $\left(\mathrm{CA}_{10}\right)$ & $135.3 \pm 0.33$ & $143.0 \pm 0.43$ & $211.3 \pm 0.21$ & $190.3 \pm 0.33$ & $109.8 \pm 0.56$ \\
\hline C.annuum var.EC:399557 $\left(\mathrm{CA}_{13}\right)$ & $137.0 \pm 0.28$ & $159.0 \pm 0.67$ & $215.8 \pm 0.31$ & $183.4 \pm 0.64$ & $111.0 \pm 0.40$ \\
\hline C. annuum var.G-4 $\left(\mathrm{CA}_{16}\right)$ & $171.3 \pm 0.31$ & $203.0 \pm 0.42$ & $250.0 \pm 0.96$ & $225.8 \pm 0.26$ & $142.7 \pm 0.24$ \\
\hline C.annuum var.CA-960 ( CA $\left._{17}\right)$ & $160.5 \pm 0.35$ & $184.0 \pm 0.41$ & $239.6 \pm 0.20$ & $213.5 \pm 0.65$ & $136.0 \pm 0.11$ \\
\hline C. annuum var. Pusa jwala $\left(\mathrm{CA}_{18}\right)$ & $194.0 \pm 0.63$ & $224.0 \pm 0.64$ & $267.0 \pm 0.63$ & $238.2 \pm 0.57$ & $168.6 \pm 0.65$ \\
\hline C.annuum var.X-235 $\left(\mathrm{CA}_{19}\right)$ & $148.5 \pm 0.32$ & $170.8 \pm 0.29$ & $225.0 \pm 0.96$ & $205.0 \pm 0.31$ & $123.0 \pm 0.95$ \\
\hline C. annuum var.NP-46A $\left(\mathrm{CA}_{20}\right)$ & $173.0 \pm 0.31$ & $210.0 \pm 0.79$ & $252.5 \pm 0.35$ & $227.6 \pm 0.66$ & $149.8 \pm 0.40$ \\
\hline C. annuum var.LCA-206 $\left(\mathrm{CA}_{21}\right)$ & $176.9 \pm 0.36$ & $216.7 \pm 0.11$ & $254.0 \pm 0.98$ & $235.0 \pm 0.70$ & $152.0 \pm 0.40$ \\
\hline C. annuum var.Trupti $\left(\mathrm{CA}_{22}\right)$ & $182.5 \pm 0.27$ & $219.0 \pm 0.68$ & $261.0 \pm 0.40$ & $249.0 \pm 0.35$ & $160.0 \pm 0.42$ \\
\hline C.annuum var.PC1 $\left(\mathrm{CA}_{25}\right)$ & $99.3 \pm 0.54$ & $134.0 \pm 0.32$ & $172.5 \pm 0.15$ & $150.9 \pm 0.42$ & $73.2 \pm 0.63$ \\
\hline C. annuum var.Surya muchi cluster $\left(\mathrm{CA}_{27}\right)$ & $86.6 \pm 0.20$ & $129.5 \pm 0.20$ & $165.0 \pm 0.43$ & $149.2 \pm 0.34$ & $58.5 \pm 0.41$ \\
\hline C.frutescens $(\mathrm{CF})$ & $72.0 \pm 0.64$ & $96.0 \pm 0.65$ & $137.5 \pm 0.20$ & $104.6 \pm 0.21$ & $44.3 \pm 0.95$ \\
\hline
\end{tabular}

${ }^{*}$ Significant at $1 \%$ level

the lowest content was recorded in C. frutescens $(\mathrm{CF})$ i.e., $72.0 \pm 0.64\left(\mathrm{M}_{1}\right), 96.0 \pm 0.65\left(\mathrm{M}_{2}\right), 137.5 \pm 0.20\left(\mathrm{M}_{3}\right)$, $104.6 \pm 0.21\left(\mathrm{M}_{4}\right)$ and $44.3 \pm 0.95\left(\mathrm{M}_{5}\right) \mathrm{mg} / 100 \mathrm{~g}$ fresh weight. Based on the mean ascorbic acid contents the eighteen genotypes were classified into three categories viz., low $(0-100 \mathrm{mg} / 100 \mathrm{~g} F W)$, medium (101- 200mg/100g

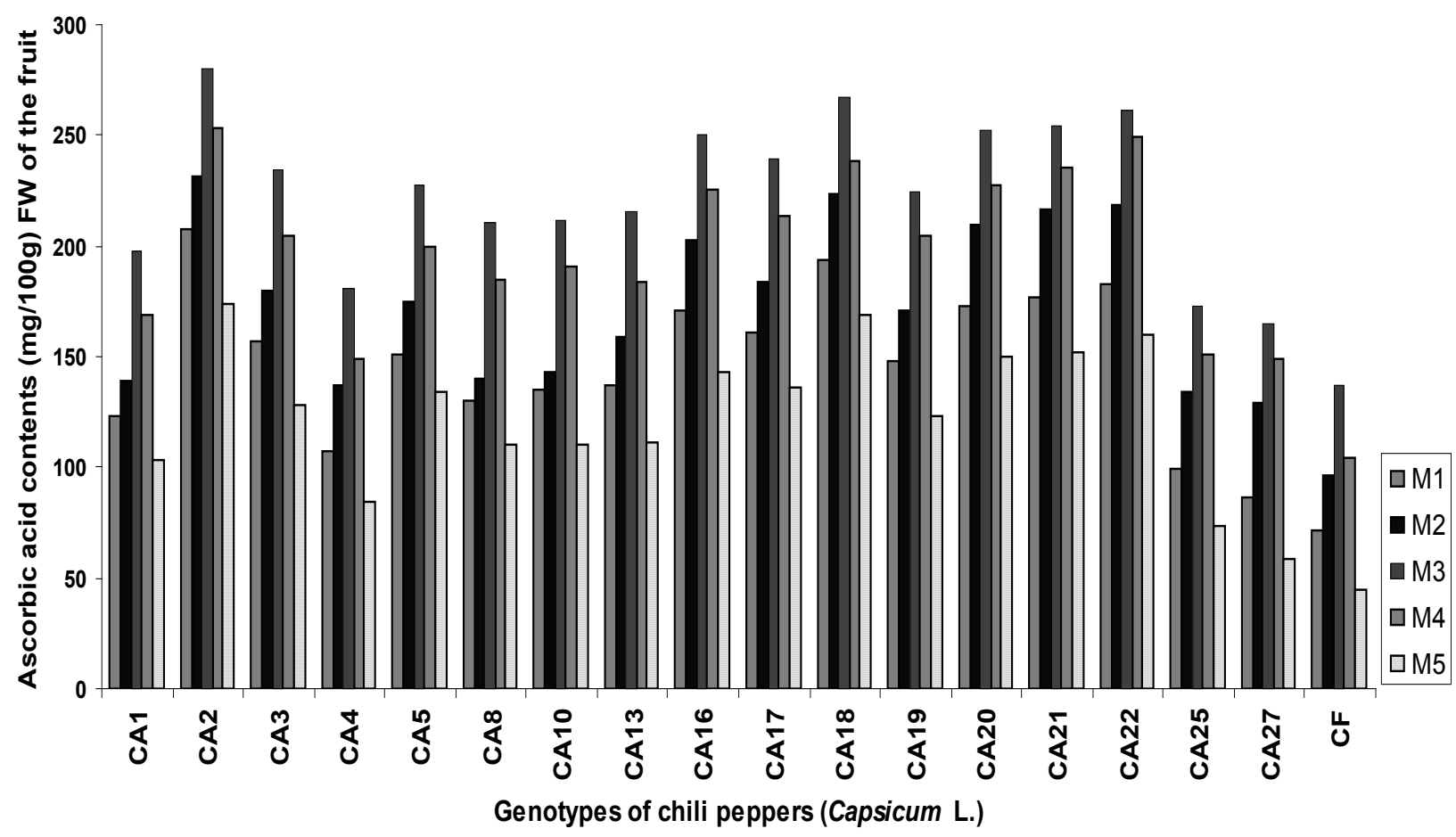

Fig.1. Ascorbic acid contents in eighteen genotypes of chili peppers (Capsicum L.) at five ripening stages. Bars mean value of ascorbic acid content. 
52

FW) and high (201- 300mg/100gFW) however, the medium category was most frequently described by Khadi et al. (1987) and Simmone et al. (1997). High content of ascorbic acid was pronounced in red ripening and most of the chili peppers were fall under medium category of ascorbic acid content however, the lowest contents were recorded in red partially dried and red fully dried fruits. This may be due to decrease in the moisture content in fruits, a similar view point is also shared by Osuna-Garcia et al. (1998), Lalitha Kumari et al. (1999), Gnayfeed et al. (2001), Robi and Sreelatha Kumari (2004) and Martinez et al. (2005) in diverse cultivars of Capsicum L. Our results suggests that six genotypes (i.e., $\mathrm{CA}_{2}, \mathrm{CA}_{18}, \mathrm{CA}_{22}, \mathrm{CA}_{21}$, $\mathrm{CA}_{20}$ and $\left.\mathrm{CA}_{16}\right)$ (Tab. 1) showed best ascorbic acid content ranged from 171.3 to $280 \mathrm{mg} / 100 \mathrm{~g} \mathrm{FW}$ in $\mathrm{M}_{1}, \mathrm{M}_{2}$, $M_{3}, M_{4}$ and $M_{5}$ fruits can be recommended in breeding programs to produce high ascorbic acid content varieties.

\section{Conclusions}

The present study reports that the ascorbic acid content in eighteen genotypes of Capsicum L showed variation from one another, among the genotypes $\mathrm{CA}_{2}$ represents more ascorbic acid. The study revealed that ascorbic acid content increased from green to red while, decreased in red partially dried and red fully dried fruits.

\section{Acknowledgements}

One of the authors (O. Aniel Kumar) is grateful to UGC-SAP, Department of Botany, Andhra University, Visakhapatnam.

\section{References}

Akhilesh, C. Mishra., R. V.Singh and H. H. Ram (2004). Studies of genetic divergence in Capsicum (Capsicum annuum L.) in Uttaranchall Hills. Capsicum and Eggplant Newsletter. $23: 45-48$

Antonious, G. F., T. S. Kochhar, R. L. Jarret and J. C. Snyder (2006). Antioxidants in hot pepper: variation among accessions. Journal of Environmental Science and Health Part B. 41:1237-1243.

Durust, N., D. Sumengen and Y. Durust (1997). Ascorbic acid and element contents of Trabzon (Turkey). J. Agric. Food. Chem. 45:2085-2087.

Gnayfeed, M. H., H. G. Daood, P. A. Biacs and C. F. Alearaz
(2001). Content of bioactive compounds in pungent spice red pepper (paprika) as affected by ripening and genotype. J. Sci. Fd. Agric. 81:1580-1585.

Howard, L. R., R. T. Smith, A. B. Wagner, B. Villalon and E. E. Burns (1994). Provitamin A and ascorbic acid content of fresh pepper cultivars (Capsicum annuum) and processed jalapenos. Journal of Food Science. 59(2):362-365.

Khadi, B. M., J. V. Goud and V. B. Patil (1987). Variation in ascorbic acid and mineral content in fruits of some varieties of chilli (Capsicum annuum L.). Plant Foods for Human Nutrition (Formerley Qualitas Plantarum). 37(1):9-15.

Lalitha Kumari, A., K. G. Reddy and I. N. Bavaji (1999). Ascorbic acid content in chilli fruits at different growth stages. Indian Spices. 36(2-3):2-3.

Lee, Y., L. R. Howard and B. Villalon (1995). Flavonoids and antioxidant activity of fresh pepper (Capsicum annuum) cultivars. Journal of Food Science.53:1448-1451.

Manju, P. R. and I. Sreelathakumari (2002). Quality parameters in hot chilli (Capsicum chinense Jacq). Journal of Tropical Agriculture.7-10

Osuna-Garcia, J. A., M. M. Wall and C. A. Waddell (1998). Endogenous levels of Tocopherols and Ascorbic acid during Fruit ripening of New Mexican-Type Chile (Capsicum annuum L.) Cultivars. Journal of Agricultural Food Chemistry. 46(12):5093-5096.

Robi, R. and Sreelatha Kumari (2004). Influence of maturity at harvest on Capsaicin and Ascorbic acid content in hot Chilli (Capsicum chinense Jacq.). Capsicum and Eggplant Newsletter. 23:13-16.

Sadasivam, S. and A. Manickham (1992). Biochemical Methods for Agricultural sciences. Wiely Estern Ltd., Madras.

Sheela, K. B., T. E. George and K. V.Peter (2004). Morphological and biochemical traits of selected accessions of bird pepper (Capsicum frutescens L.). Capsicum and Eggplant Newsletter. 23:33-36.

Martinez, S., L. Mercedes, M. Gonzalen-Raurich and A. Bernardo Alvarez (2005). The effects of ripening stage and processing systems on vitamin $\mathrm{C}$ content in sweet peppers (Capsicum annuum L.). International journal of Food Sciences and Nutrition. 56(1):45-51.

Simonne, A. H., E. H. Simonne, R. R. Eitenmiller, H. A. Mills and N. R. Green (1997). Ascorbic acid and provitamin A contents in unusually colored bell peppers (Capsicum annuum L.). J. Food Comp. Anal. 10:299-311. 